\title{
Spatiotemporal expression of histone acetyltransferases, p300 and CBP, in developing embryonic hearts
}

\author{
Guozhen Chen ${ }^{1}$, Jing Zhu' ${ }^{1}$, Tiewei Lv1, Gang Wu1 ${ }^{1}$, Huichao Sun ${ }^{1}$, \\ Xupei Huang ${ }^{2}$ and Jie Tian*1
}

Address: ${ }^{1}$ Department of Cardiology, The Children's Hospital of Chongqing Medical University, Chongqing, PR China and ${ }^{2}$ Department of Basic Science, Charlie E. Schmidt College of Biomedical Science, Florida Atlantic University, Boca Raton, FL, USA

Email: Guozhen Chen - chenguozhen7954@yahoo.com.cn; Jing Zhu - zhujing310@yahoo.com.cn; Tiewei Lv - ltw200145@yahoo.com.cn; Gang Wu - wugang70112@yahoo.com.cn; Huichao Sun - sunshinechao@yahoo.com.cn; Xupei Huang - xhuang@fau.edu;

Jie Tian* - jietian@cqmu.edu.cn

* Corresponding author

Published: 23 February 2009

Journal of Biomedical Science 2009, 16:24 doi:10.1 I86/1423-0I27-16-24

This article is available from: http://www.jbiomedsci.com/content//6/I/24

(c) 2009 Chen et al; licensee BioMed Central Ltd.

This is an Open Access article distributed under the terms of the Creative Commons Attribution License (http://creativecommons.org/licenses/by/2.0), which permits unrestricted use, distribution, and reproduction in any medium, provided the original work is properly cited.
Received: 15 January 2009

Accepted: 23 February 2009

\begin{abstract}
Histone acetyltransferases (HATs), p300 and cAMP response element binding protein (CREB)binding protein $(\mathrm{CBP})$ are two structurally related transcriptional co-activators that activate expression of many eukaryotic genes involved in cellular growth and signaling, muscle differentiation and embryogenesis. However, whether these proteins play important and different roles in mouse cardiogenesis is not clear. Here, we investigate the protein distributions and mRNA expression of the two HATs in embryonic and adult mouse heart during normal heart development by using immunohistochemical and RT-PCR techniques. The data from immunohistochemical experiments revealed that $\mathrm{P} 300$ was extensively present in nearly every region of the hearts from embryonic stages to the adulthood. However, no CBP expression was detected in embryonic hearts at day E7.5. CBP expression appeared at the later stages, and the distribution of CBP was less than that of $\mathrm{p} 300$. In the developmental hearts after E10.5, both for $\mathrm{p} 300$ and CBP, the mRNA expression levels reached a peak on day EI0.5, and then were gradually decreased afterwards. These results reveal that both $\mathrm{p} 300$ and CBP are related to embryonic heart development. The dynamic expression patterns of these two enzymes during mouse heart development indicate that they may play an important role on heart development. However, there is a difference in spatiotemporal expression patterns between these two enzymes during heart development. The expression of $\mathrm{p} 300$ is earlier and more predominate, suggesting that $\mathrm{p} 300$ may play a more important role in embryonic heart development especially during cardiac precursor cell induction and interventricular septum formation.
\end{abstract}

\section{Background}

The heart is the first functional organ during embryogenesis and its formation is initiated in a region of anterior mesoderm known as the cardiac crescent at about embryonic day 7.5 (E 7.5) in mice. Soon after their specification, the cardiac crescent from cardiac precursor cells converges along the ventral midline of the embryos to form the linear heart tube at around day E 8.5, which undergoes looping, chamber growth, specification and ultimately fourchamber formation $[1,2]$. 
Chromatin-remodeling and chromatin-modifying factors play a critical role in the process of cardiogenesis [3]. Histone acetyltransferases (HATs) and chromatin remodeling complexes facilitate chromatin opening and promote gene transcription [4]. The transcriptional co-activator p300 and CBP are HATs that regulate gene expression by acetylating histones and play central roles in a wide range of cellular processes during heart development [5-7]. CBP and p300 are highly homologous proteins that are well conserved among eukaryotic cells and have been considered to be functionally equivalent [8]. However, the reports from recent studies indicate that the two proteins may have different distribution patterns and functions in embryogenesis [9-14].

The role of CBP and p300 during the development was first revealed by the observations that human CBP gene was disrupted in a dominant genetic disorder, RubinsteinTaybi Syndrome (RTS), which was characterized by craniofacial and limb defects, mental retardation as well as developmental anomalies of the eye, heart, kidney, lung, skin and testes [15]. In the subsequent gene disruption experiments in mice, it has been reported that mammalian development was tightly relevant to the CBP and p300 since knockout of p300 in mice resulted in an embryonic death of homozygous mutants during the days E 9 and E11.5 manifesting the defects in neurulation, cell proliferation, and heart development [16]. The CBP null animals exhibit a phenotype very similar to that observed in the p300 null mice. The homozygous mutants of CBP died on days E10.5-E12.5 with a massive hemorrhage in central nervous system, cranial neural tube closure defects and a developmental retardation in both primitive and definitive hematopoiesis. However, abnormal heart formation was not observed in CBP-deficient embryos [17]. Inactivation of acetyltransferase (AT) domain of murine p300 or CBP using a knock-in approach resulted in an increase of embryonic or neonatal lethality in mice. In addition, p300 AT domain mutations can cause multiple defects in the heart, lung and intestine formation, indicating that p300 AT plays a critical role in organogenesis [18]. p300 and CBP are generally present in mouse oocytes and pre-implanted embryos, and they experience the specific pattern of trafficking from the cytoplasm to the nucleus at different stages during the growth of oocytes [12].

Although it is well established that CBP and p300 are involved in transcription and development, scant information is available about the expression patterns and distributions of these two HATs in the hearts during the development. In the present study, we have systematically analyzed the p300 and CBP expressions during mouse cardiogenesis using RT-PCR and immunohistochemical techniques. The dynamic expression patterns of these two enzymes during mouse heart development indicate that they may play an important role on heart development. The expression of p300 is earlier and more predominate, suggesting that p300 may play a more important role in embryonic heart development especially during cardiac precursor cell induction and interventricular septum formation.

\section{Materials and methods \\ Experimental animals}

28-32 g KM mice were purchased from Experimental Animal Center of Chongqing Medical University. Animals were mated at 5:00 pm and females examined for a vaginal plug the following morning. The noon of the day when a vaginal plug was confirmed was considered as E0.5. Female mice were killed by cervical dislocation. The whole embryos at E7.5-E9.5 were collected. The whole hearts from embryonic mice at E10.5-E18 and from 1day-old neonatal mice or from adult mice were collected accordingly. All procedures were approved by the Animal Care and Use Committee at the Chongqing Medical University (Chongqing, China)

\section{Immunohistochemical experiments}

For immunohistochemical experiments, 3 embryos or 3 embryonic hearts or hearts from different mice at the same developmental stage were used and the embryo or heart samples were immediately fixed in fresh neutral formalin $(37 \%-40 \%$ formalin, three-distilled water $880 \mathrm{ml}$, $\mathrm{NaH}_{2} \mathrm{PO}_{4} 4 \mathrm{~g}, \mathrm{Na}_{2} \mathrm{HPO}_{4} 13 \mathrm{~g}$ ) for 3-48 hours depending on the stage of the samples and embedded in paraffin wax. Thereafter, the specimens were sectioned at a thickness of $7 \mu \mathrm{m}$. Sections were deparaffinized, hydrated through gradual ethanol steps, and briefly rinsed in water. Endogenous peroxidases were inactivated by incubating the slides in $3 \% \mathrm{H}_{2} \mathrm{O}_{2}\left(30 \% \mathrm{H}_{2} \mathrm{O}_{2} 10 \mathrm{ml}\right.$, methanol 90 $\mathrm{ml}$ ) for 10 minutes. Antigens retrieval was performed by boiling the slides in citrate buffer solution (trisodium citrate $3 \mathrm{~g}$, citric acid $0.4 \mathrm{~g}, 1000 \mathrm{ml}$ three-distilled water, $\mathrm{PH}$ 6.0) for 3 times and each time was separated by an interval duration 8 minutes. The unspecific protein binding sites on the sections were preblocked with $10 \%$ goat serum for $10 \mathrm{~min}$. Slides were incubated with primary antibodies. CBP and p300 primary antibodies were purchased from Abcam Inc. (Cambridge, MA). Mouse monoclonal antip300 (ab3164) was diluted to 1:25 in PBS. Rabbit polyclonal anti-CBP (ab32646) was diluted to 1:700 in PBS. Samples were incubated with respective antibodies for overnight at $4{ }^{\circ} \mathrm{C}$ and samples without primary antibodies were used as controls. Slides were then incubated with corresponding biotin-conjugated secondary antibody and HRP-conjugated third antibody for $30 \mathrm{~min}$ at $37^{\circ} \mathrm{C}$ in a wet box, respectively. Color reaction was generated for 35 min with $\mathrm{DAB}$ and stopped by rinsing the slides in distilled water. Finally, the slides were re-stained with hema- 
toxylin and sealed with neutral gum. All slides were viewed using a Leica TCS SL microscope (Leica LCS Version 2.0).

\section{Total RNA isolation and RT-PCR analysis}

Total RNA was isolated and reverse transcribed from pooled hearts at each stage (5-10 hearts per stage), ranging from E10.5 to E18 embryos, and from neonatal day 1 $(\mathrm{n}=3)$ or from adult mice $(\mathrm{n}=1)$ according to a reference previously described [19]. The extraction was performed using an Eukaryotic Perfect RNA Extract Kit (Genemega, China) following the manufacturer's protocols. Contaminating endogenous RNase was removed by treatment with DEPC (Amresco, USA) for 8 hour at room temperature. First-strand cDNA synthesis was carried out at $42^{\circ} \mathrm{C}$ for 1 hour using $6 \mu$ l of total RNA, oligo-dT primers and Superscript RNase H-reverse transcriptase (Promega Inc, Madison, WI.) according to the manufacturer's instruction. PCR was performed using $2 \mu$ of First-Strand reaction mixture. As a negative control for genomic DNA contamination each sample was subjected to the same reaction without reverse transcriptase.

The specific primers were designed to detect mouse p300, CBP and $\beta$-actin as follows: p300 (forward) 5'-GCCAAGTATGCCAACCCTAA-3';

(reverse), 5'-TGTTCATTTGCTGAGCTTGG-3'.

CBP (forward) 5'-TGGAGTGAACCCCCAGTTAG-3';

(reverse) 5'-TTGCTTGCTCTCGTCTCTGA-3'.

$\beta$-actin (forward), 5'-TAGCCACGCTCGGTCAGGATCTTCAT-3';

(reverse), 5'-ACCAACTGGGACGACATGGAGAAGATC-3'.

Amplification conditions for p300 were a 7 minute hot start at $95^{\circ} \mathrm{C}$ followed by 35 cycles of $95^{\circ} \mathrm{C}$ for 1 minute, $60^{\circ} \mathrm{C}$ for $40 \mathrm{sec}$, and $72^{\circ} \mathrm{C}$ for 1 minute and a final extension at $72^{\circ} \mathrm{C}$ for 5 minute. The conditions for CBP were a 5 minutes hot start at $94^{\circ} \mathrm{C}$ followed by 35 cycles of $94^{\circ} \mathrm{C}$ for 1 minute, $54^{\circ} \mathrm{C}$ for $30 \mathrm{sec}$, and $72^{\circ} \mathrm{C}$ for $30 \mathrm{sec}$ and a final extension at $72^{\circ} \mathrm{C}$ for 5 minutes. Conditions for $\beta$ actin were a 5 minutes hot start at $94^{\circ} \mathrm{C}$ followed by 30 cycles of $95^{\circ} \mathrm{C}$ for 1 minute, $58^{\circ} \mathrm{C}$ for $40 \mathrm{sec}$, and $72^{\circ} \mathrm{C}$ for $40 \mathrm{sec}$ and a final extension at $72^{\circ} \mathrm{C}$ for 5 minute. All amplification products were resolved in a $1.5 \%$ agarose gel and sequencing confirmed the identity of each PCR amplified product and electrophoresis and the bands were analyzed with a Gelatin image formation meter (Bio-Rad) and Quantity One Version 4.4. The quantity of $\beta$-actin was used as an internal control to normalize the relative expression levels of p300 mRNA and CBP mRNA. Each experiment was repeated at least three times.

\section{Western Blotting}

Nuclear proteins from fresh E10.5 embryo hearts were extracted using the Nuclear Extract Kit (ActiveMotif, Inc, Carlsbad, CA) according to manufacturer's instructions. Nuclear proteins were separated and electrophoresed on $6 \%$ Bis-Tris polyacrylamide gels and then transferred to a PDVF membrane. Blots were blocked in TBS plus 5\% nonfat milk for $1 \mathrm{~h}$. Then the blots were probed with either antibody against p300 (Abcam, ab3164, 1:200 dilution) or CBP (Abcam, ab32646, 1:1000 dilution) at $4{ }^{\circ} \mathrm{C}$ overnight, and HRP conjugated goat anti-IgG antibody was used as the secondary antibody. Protein bands were revealed with an Enhanced Chemiluminescence Luminal reagent (Santa Cruz, CA), scanned and analyzed with Quantity One Version 4.4 software.

\section{Statistical analysis}

Data were expressed as mean \pm standard deviation (SD) and statistical differences in measured mRNA level between various experimental groups were assessed using an independent F-test with SAS (version 9). All tests used a $\alpha$ level of 0.05 .

\section{Results}

\section{Distributions of $\mathrm{p} 300$ and CBP during heart development}

The specificity of the antibodies was confirmed using nuclear protein extracts of E10.5 embryo hearts by Western blotting. As shown in Figure 1, both p300 (A, B) and CBP (C, D) protein expression was detected in E10.5 embryo hearts using the antibodies described in the "Materials and Methods".

We further analyzed the distribution of p300 and CBP proteins using immunohistochemical techniques in

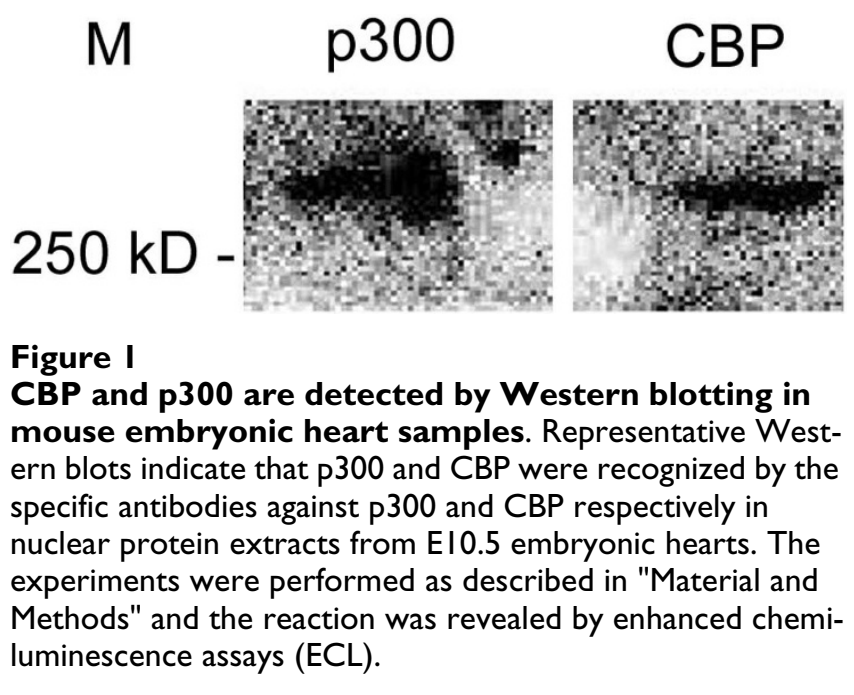


mouse heart tissues from the early embryonic stages (E7.5) to the adult stages.

We showed that during the early embryonic heart development stages (E7.5-E9.5), p300 was highly expressed in crescent-shaped cardiogenic plate (future myocardium) at E7.5 (Figure 2A), while no CBP expression was detected in this region at the same stage (Figure 2D). We also showed that p300 was highly expressed at E8.5 in the fusing heart tubes including endocardium primordium and myoepicardial mantle, the presumptive regions of myocardium and epicardium (Figure 2B). Similarly, we found high level expression of p300 at E9.5 in the looping heart tubes which include all cardiac compartments, i.e. primary atrial and ventricular myocardium as well as outflow tract (Figure 2C). CBP was also observed in these regions at E8.5 and E9.5, however, the protein level was much less compared to p300 (Figures 2E \& 2F).

During the chamber specific forming and septation stages(E10.5-E15.5), the mouse heart morphological changes were observed as follows. The mouse heart was unseptated at E9.5, and looped tube formed which had three oncoideses, i.e. bulbus cordis, primary ventricle and primary atria from top to end. As heart developed further, confined atrioventricular canal (AVC) formed between atria and ventricle. Meanwhile, the endocardial cushions (EC) became visible at E10.5 in the AVC. At this stage, ventricular trabeculae were evidently visible within the presumptive right ventricle (RV) and left ventricle (LV). By E11.5, there had been evidently visible EC and gradually forming primary atrial septum (PAS) as well as considerable growth of the muscular interventricular septum (IVS) so that the RV and LV were now separated apically, which, at this stage, the ridges within the outflow tract (OFT) had started to appear and face to fuse, and the mesenchymal swellings that would become the atrioventricular valves were visible. By E13.5, second atrial septum had completely formed, and aortico-pulmonary septum had formed so that the pulmonary artery and ascending aorta were separated. Meanwhile, atrial trabeculae were visible. By E14.5, membranous IVS resourced from EC had fused to muscular IVS. By E15.5, tricuspid and mitral valves had formed at the right and left atrioventricular foramen, respectively. As shown in Figure 3, in these stages, p300 was highly expressed in developing chamber walls, i.e. ventricular myocardium, atrial myocardium and interatria septum (IAS), IVS, trabeculae, atrioventricular EC and OFT which gradually developed into pulmonary artery and ascending artery (Figures 3A-I). However, CBP distribution was not so even as we found a higher distribution in atrioventricular myocardium and a relatively lower distribution in atrioventricular valves, trabeculae and OFT and a very low distribution in the developing muscular IVS and membranous IVS (Figures 3J-R).
At late fetal developmental stages (from E16.5 till born), the heart has complete four chambers separated by IAS, IVS and the atrioventricular valves. As the heart developed, the myocardial cell number increases, which resulted in a bigger heart. In embryonic hearts (E16.5 and E18), we found that p300 was highly expressed in myocardium and trabeculae, but relatively lowly expressed in septum and valves (Figures $4 \mathrm{~A} \& 4 \mathrm{~B}$ ). We also showed that CBP expressions were relatively low in myocardium and trabeculae, as well as in muscular IVS and lower expressions in membranous IVS (Figures 4G \& 4F). Similar findings were observed in the postnatal day 1 hearts (Figures $4 \mathrm{C}, \mathrm{D}, \mathrm{H}, \mathrm{I})$.

In adult mouse hearts, relatively high expressions of $\mathrm{p} 300$ were observed in chamber walls (Figure $4 \mathrm{E}$ ) and low expressions of p300 were found in septum and valves (data not shown). However, low expressions of CBP were observed in chamber walls (Figure 4J) and muscular IVS. CBP in membranous IVS was extremely low (data not shown).

\section{p300 and CBP mRNA expressions during mouse heart development}

We further investigated p300 and CBP mRNA expression levels during mouse cardiogenesis using RT-PCR techniques. This enabled a comparison of the semi-quantitative expression of p300 and CBP mRNA level at different developmental stages to be made. These data were expressed as a ratio of $\mathrm{p} 300$ or CBP to $\beta$-actin expression levels. The earliest time of collecting cardiac tissues for RTPCR was day E10.5 which was the earliest stage to gain the completely isolated heart. The expression levels of both p300 and CBP gradually diminished after day E12.5 but a weak expression was still observed on day 1 after birth and in adult hearts (Figure 5). The mRNA expression data are consistent with the results we obtained from the immunohistochemical studies.

\section{Discussion}

The current model of mammalian heart development indicates that the crescent primary heart primordium derived first from cardiac precursor cells (on day E7.5 in mice) undergoes fusion to form primary linear heart tube (on day E8.5). Then the tube loops to form primary chamber (E9.5). The chamber separation occurs on E10.5 E15.5 to ultimately form a four-chambered heart and the heart continue to grow till the consummation. During the process, cardiac cell differentiation plays a critical role to allow certain genes to be expressed at a given stage of the development [20]. The selection applies to either the activation or the repression of certain cardiac genes. Modification of histone acetylation by HATs is an important pattern to control the gene expressions. Both p300 and CBP are the members of the HATs family and they are a 
p300
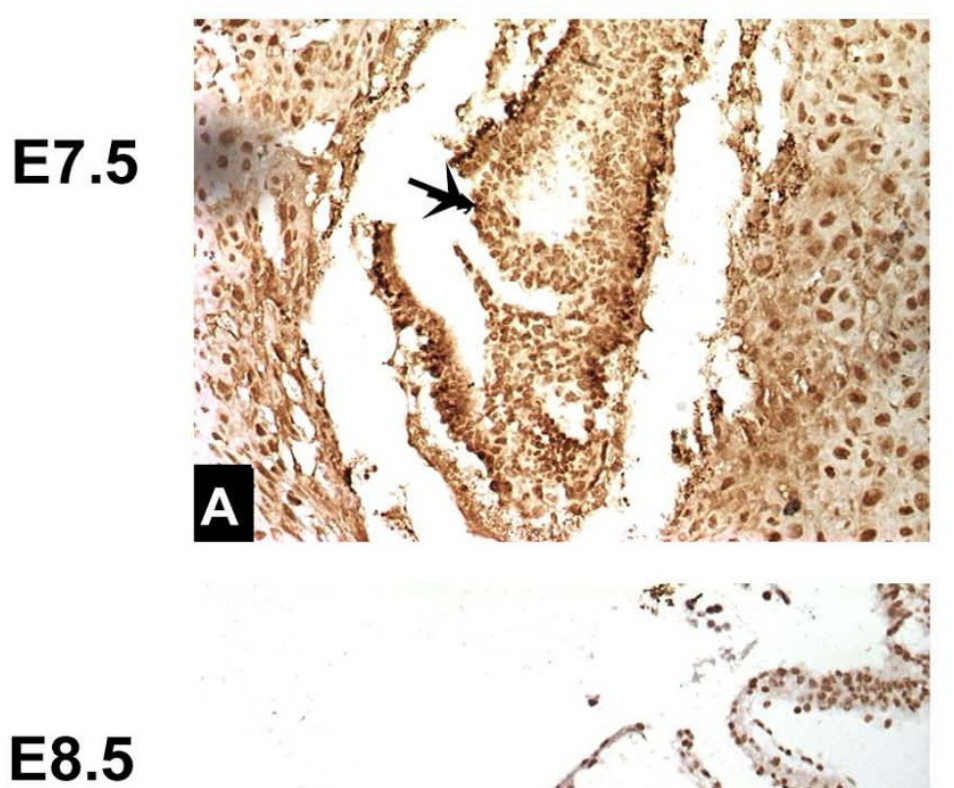

E9.5

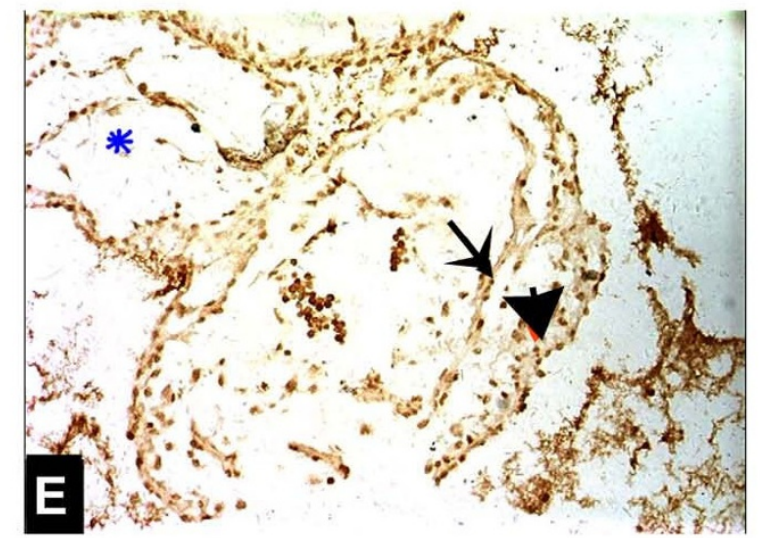

CBP
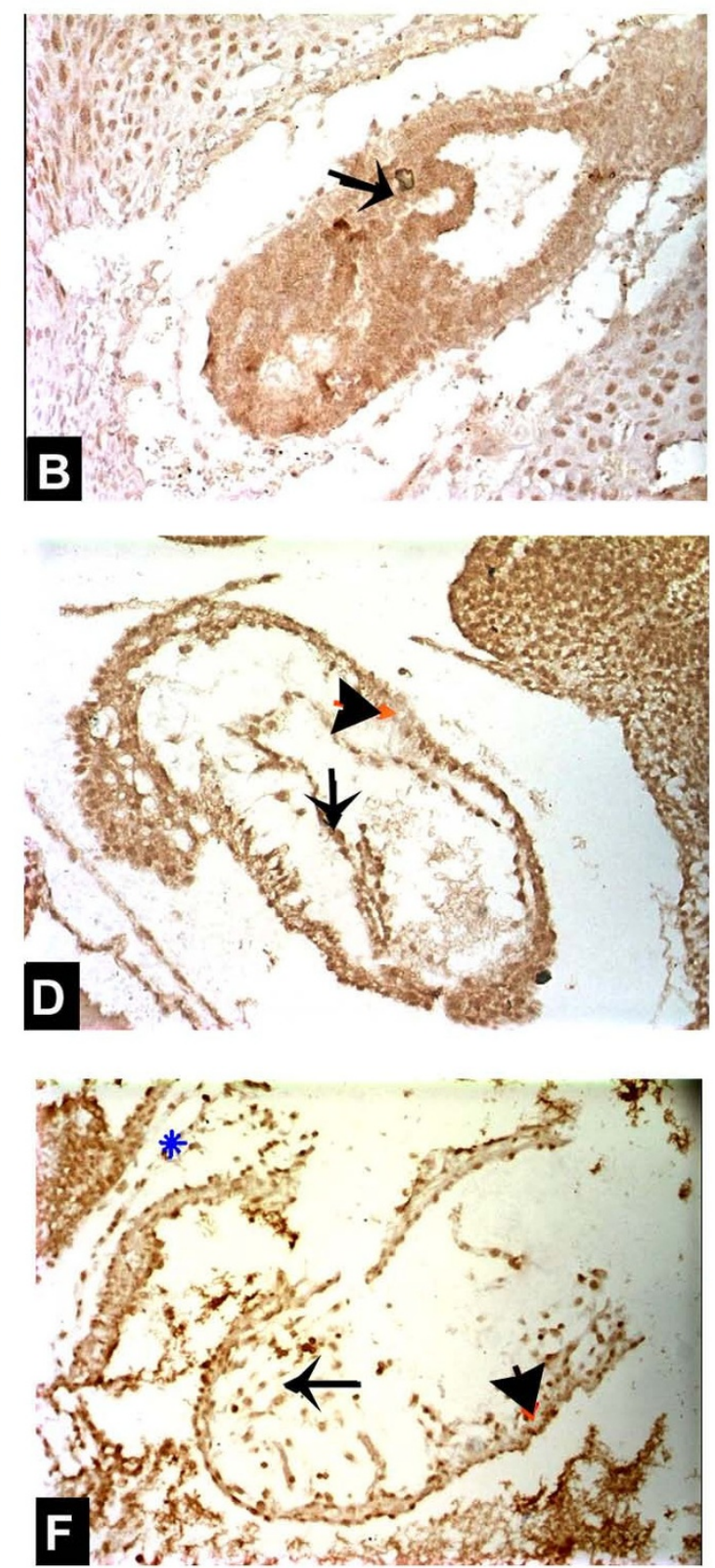

Figure 2

Protein expression patterns of p300 and CBP in early embryonic hearts. Lateral view of E7.5 embryo shows a high expression of $\mathrm{p} 300$ in cardiac crescents (arrow) at the anterior of the embryo (A). No expression of CBP was detected in cardiac crescents of a E7.5 embryo (arrow)(B). Lateral view of E8.5 embryo shows a high expression of p300 in linear heart tube at midline of the embryo including endocardium primordium (arrow) and myoepicardial mantle (arrowhead) which are the presumptive regions of myocardium and epicardium (C). Lateral view of E8.5 embryo shows a relatively low expression of CBP in the endocardium primordium (arrow) and myoepicardial mantle (arrowhead)(D). Lateral view of E9.5 embryo shows a high expression of $\mathrm{p} 300$ in looping heart tube at the left of the embryo including endocardium primordium (arrow) and myoepicardial mantle (arrowhead)(E). Lateral view of E9.5 embryo shows a relatively low expression of CBP in the looping heart tube including endocardium primordium (arrow) and myoepicardial mantle (arrowhead). Magnification: $\times 200$. 


\section{p300}

\section{E10.5}

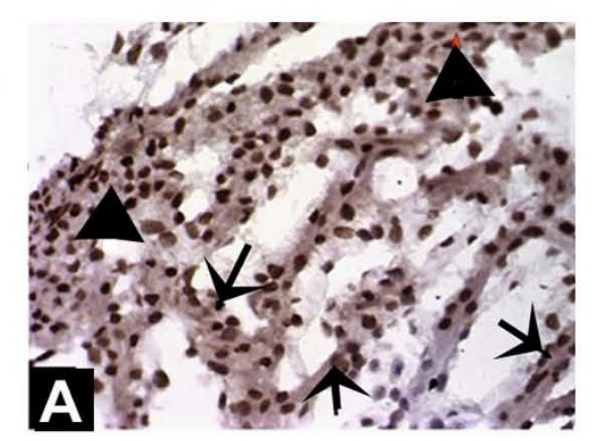

E11.5

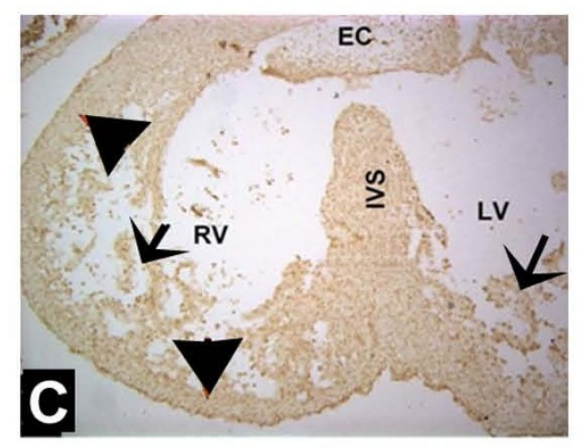

E12.5

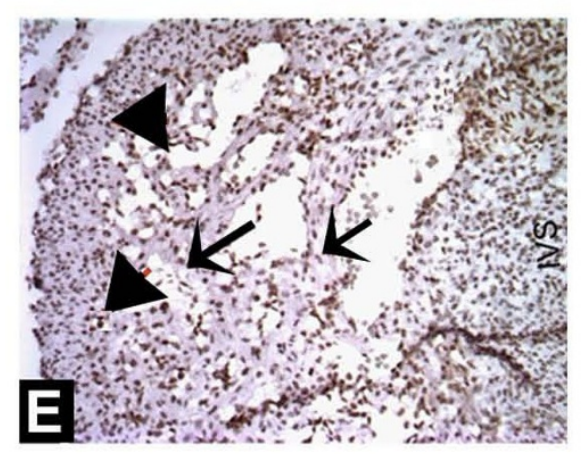

E14.5

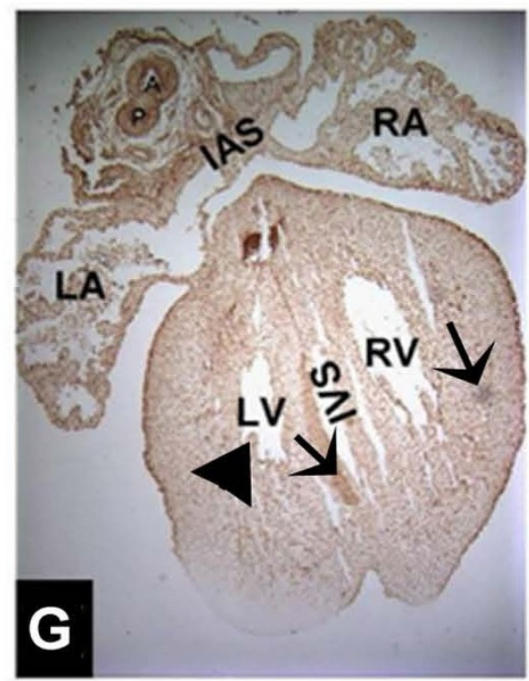

CBP
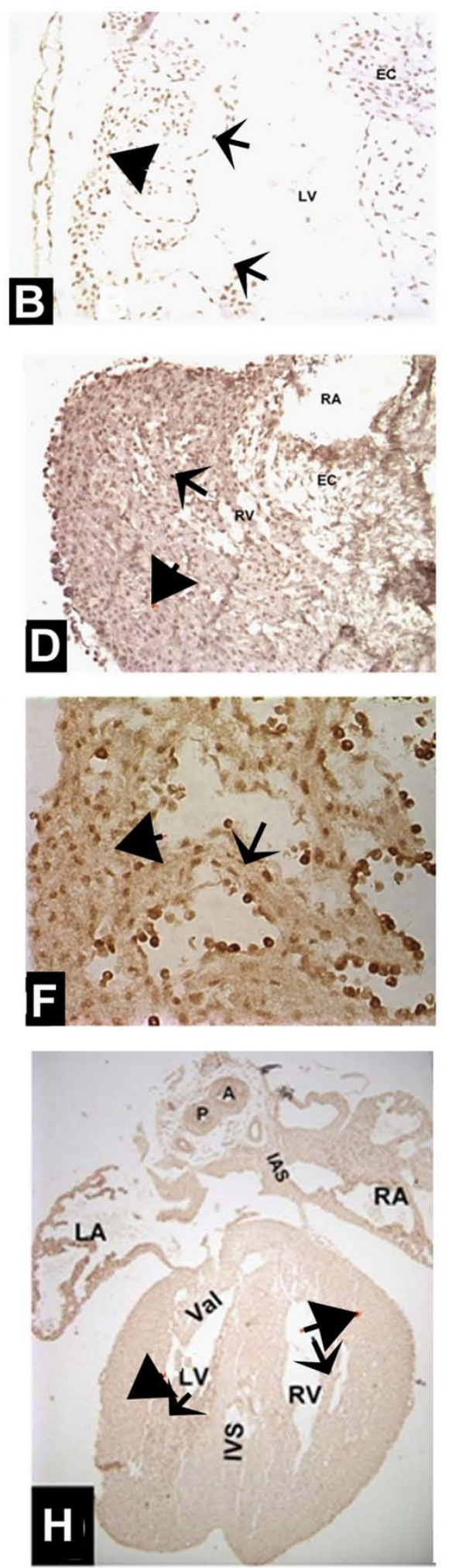

Figure 3 (see legend on next page) 
Figure 3 (see previous page) Expressions of p300 and CBP in embryonic hearts during chamber formation and septation stages from EI 0.5 to EI5.5. EI0.5 embryo heart shows a high p300 expression (A) and a relative low expression of CBP (B) in most cardiac compartments, in particular in the trabeculae (arrow) and ventricular myocardium (arrowhead). C shows a high expression of P300 at EII.5 in atria and ventricle walls (arrowhead), ventricular trabeculae (arrow). D shows that a high expression of CBP was found at EII.5 in atrioventricular myocardium (arrowhead), a relatively low expression of CBP was found in trabeculae (arrow) and OFT. At EI2.5, p300 is highly expressed in atria and ventricle walls (arrowhead), ventricular trabeculae (arrow)(E). A similar CBP expression pattern is shown in EI2.5 embryos (F) in cardiac walls (arrowhead) and trabeculae (arrow). In EI4.5 embryonic heart, $\mathrm{p} 300$ is highly and extensively expressed in walls, ventricular trabeculae, muscular IVS and nascent membranous IVS, nascent pulmonary artery and aorta (G). At the same stage, CBP is highly expressed in atrioventricular myocardium and lowly expressed in atrioventricular valves, trabeculae and OFT $(H)$.

pair of closely homologous co-activators that are often referred to as a single entity [21]. Although it has been reported that $\mathrm{p} 300$ and $\mathrm{CBP}$ are essential for multi-organogenesis [8-14], little is known about their locations and dynamic expression in the heart during the development. In this study, we have investigated the distributions of these two enzymes in the heart during the heart formation from the very beginning of the cardiac crescent forming at E7.5 to adult heart using immunohistochemistry and RTPCR to better understand the roles of these two enzymes on cardiogenesis. Our RT-PCR data have shown that both $\mathrm{CBP}$ and p300 are present in the heart during the development from E10.5 till adulthood with a similar dynamic variance and a high expression at the early stages of chamber septation. In addition, we have observed that p300 is highly expressed in the heart from E10.5 to E11.5 with a peak expression at E10.5 whereas CBP is highly expressed from E10.5 to E12.5 and with a peak expression at the same time. Expression of both p300 and CBP is gradually decreased in the subsequent heart development stages till the postnatal and adulthood stages, suggesting that p300 and CBP are required for gene expression during the heart development. Furthermore the findings also support the notion that both enzymes have a concomitant transcriptional regulation during cardiogenesis.

However the immunohistochemical data reveal different distribution patterns of p300 and CBP in early stages of heart development, suggesting a potential functional difference between these two enzymes. In the stage of cardiac precursor cells induction (day E7.5), p300 has a much higher distribution than CBP in crescent-shaped cardiogenic plate, indicating that p300 probably plays a more important role on cardiac progenitor cells induction and migration. p300 is highly distributed in all areas of heart including cardiac walls, septum, trabeculae, developing cardiac cushions and valves during the subsequent stages from the fetal development till the postnatal day 1. In adult mouse hearts, a relatively high presentation of p300 is observed in the walls and a lower distribution is seen in the septum and the valves. Unlike p300, CBP has a different distribution pattern. A relatively high presentation of
CBP is found in the early linear cardiac tube at E8.5 and in the looping cardiac tube at E9.5. From the chamber septation and late heart development stages till the postnatal day 1. CBP is found with a high concentration in atrioventricular walls and with a less content in atrioventricular valves, trabeculae, and a very low level in developing muscular IVS and a lower expression in forming membranous IVS. In adult mouse hearts, a low level of CBP is observed in walls and muscular IVS and extremely low content of CBP is observed in membranous IVS. These findings suggest that both p300 and CBP may participate in the morphogenesis of heart, which is in consistent with the results from the RT-PCR experiments in this study. However p300 may have more important functions than CBP for heart development, since it has a broader distribution in the heart especially during the stages of trabeculation and cardiac septum formation. These observations are consistent with the previous studies $[22,23]$.

In general, the expression of p300 and CBP is ubiquitous in mammalians $[9,16]$. The phenotypes observed in transgenic mice harboring mutated CBP or p300 indicate that both CBP and p300 are essential for normal embryogenesis [16]. Our experimental results suggest that p300 is ubiquitously expressed in developing hearts and throughout postnatal as well as in adult hearts. The distribution pattern of p300 in the heart during development is similar to that of CBP with an expectation that no CBP is found on day E7.5.

Although p300 and CBP have great similarity in both biochemical structures and functions, increasing researches have shown that CBP and p300 might possess distinct developmental functions due to differences in their distribution and expression patterns. Animals with deficiency of p300 or CBP exhibited abnormal phenotypes suggesting that CBP and p300 cannot be replaced in the homozygous mutant mice $[16,17]$. It is known that patients suffering from Rubinstein-Taybi syndrome, an autosomal dominant syndrome characterized by abnormal growth and mental retardation as well as abnormal heart development, commonly have CBP gene mutations 


\section{p300}

\section{E 18}

\section{Postnatal Day 1}
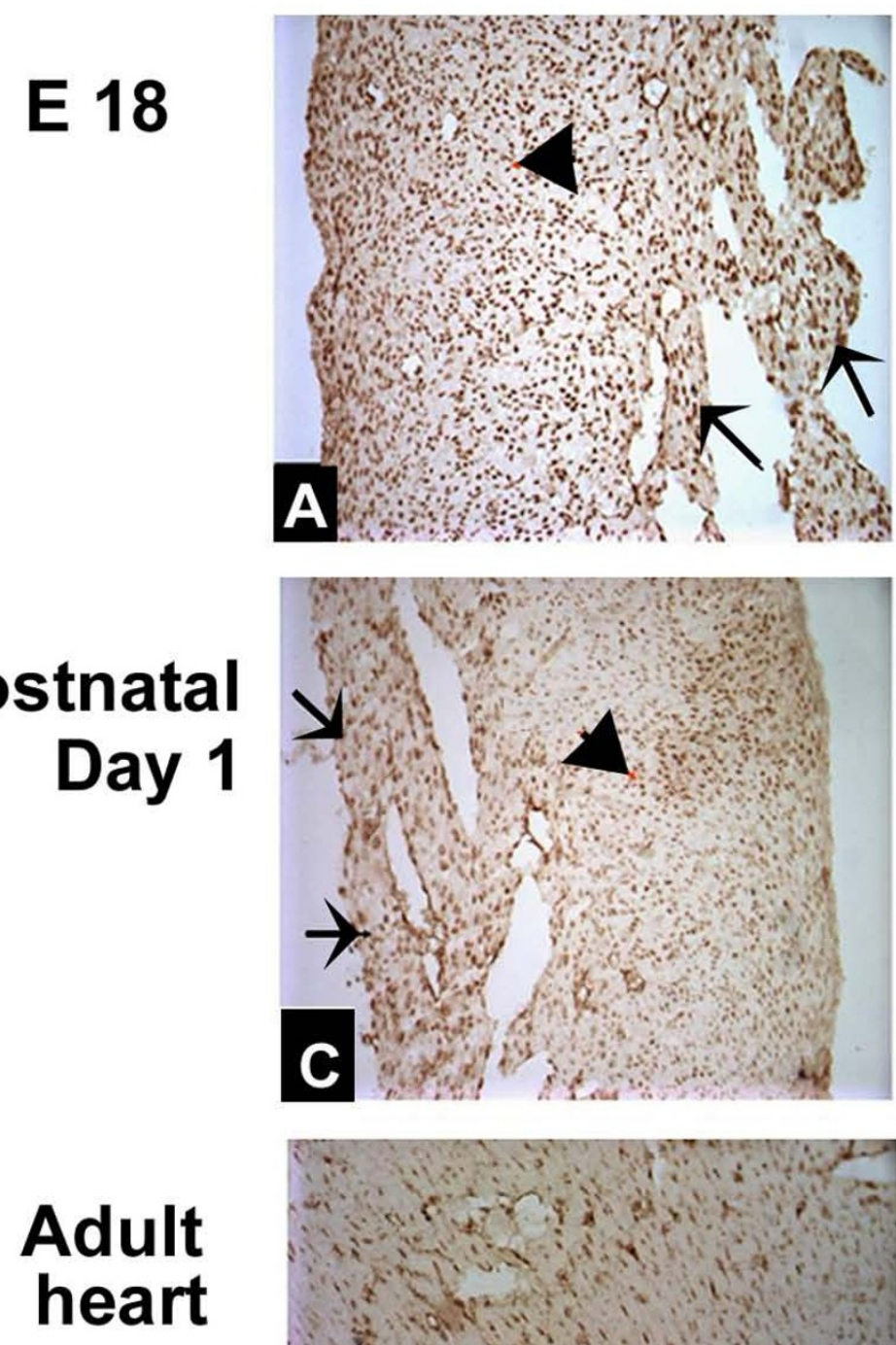

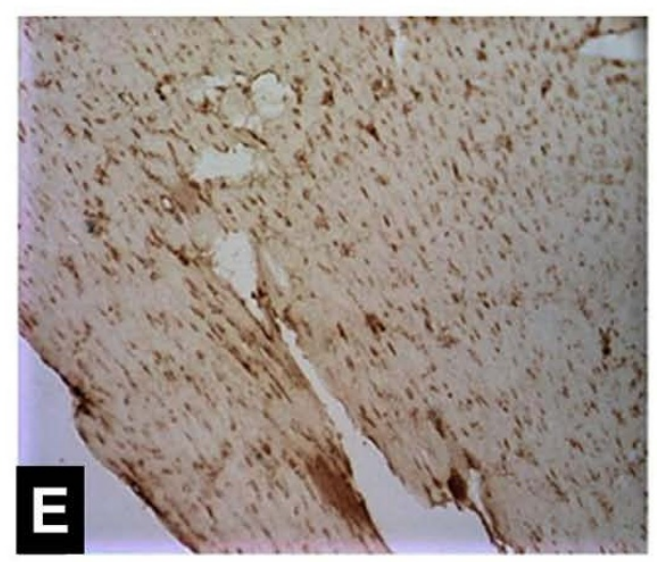

CBP
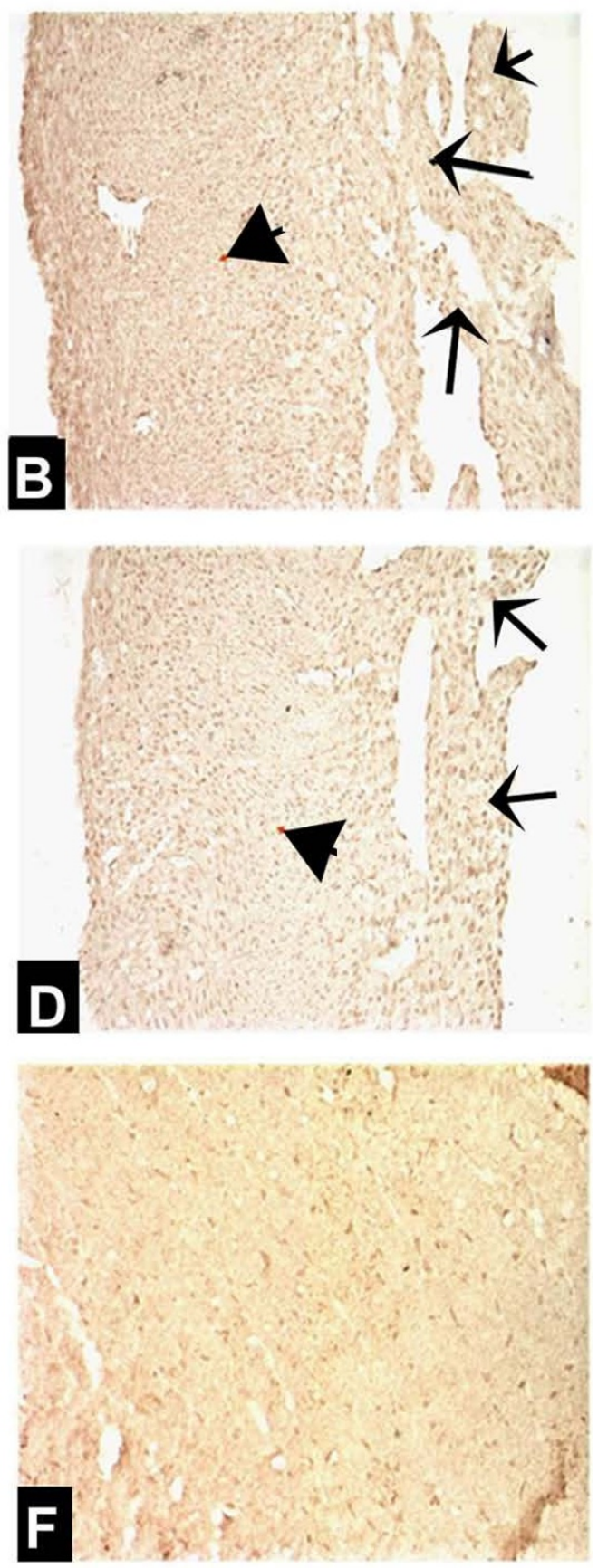

Figure 4

p300 and CBP expressions in mouse hearts at late fetal stages, postnatal day $I$ and adulthood stages. p300 is highly expressed in myocardium (arrowhead) and trabeculae (arrow) but relatively lowly expressed in septum and valves in EI8 embryonic heart (A) and in postnatal day I heart (C). A relatively low expression of CBP in myocardium (arrowhead) and trabeculae (arrow) was shown in El8 embryonic heart (B) and postnatal day I heart (D). In adult mouse hearts, both p300 (E) and $C B P(F)$ expression were low. 
(A)

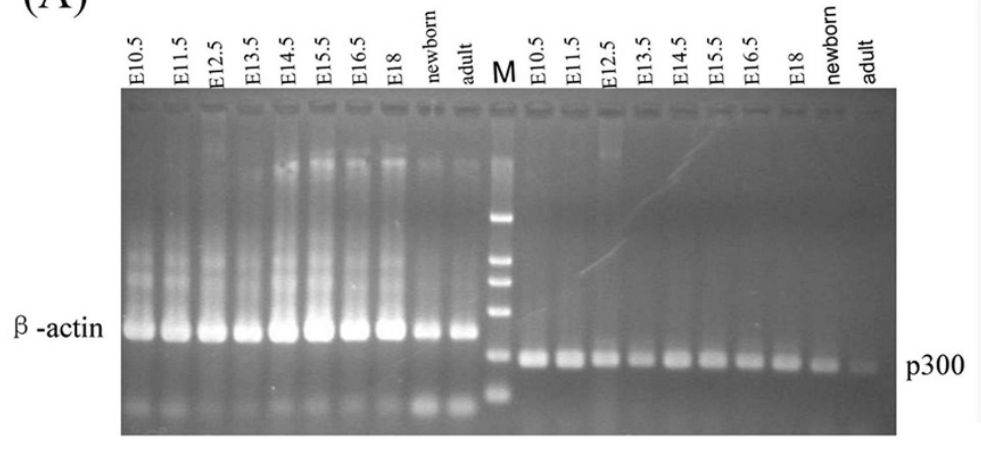

(C)

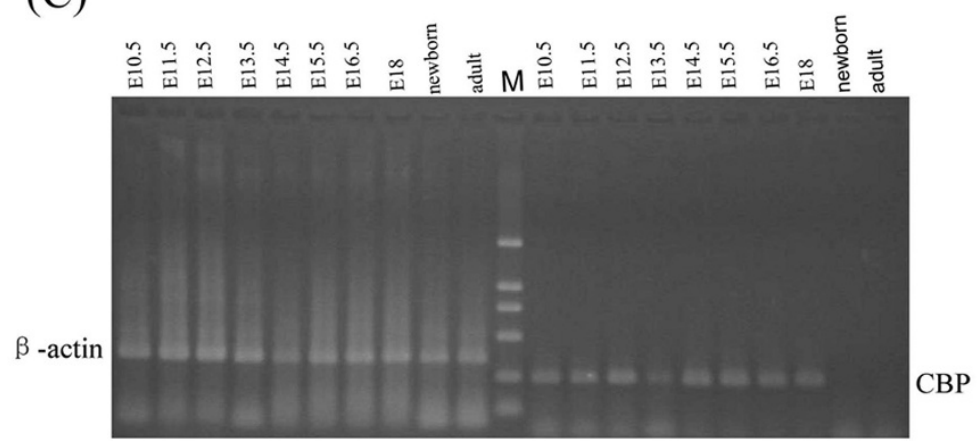

(B)

p300 mRNA expression level normalized by B-actin

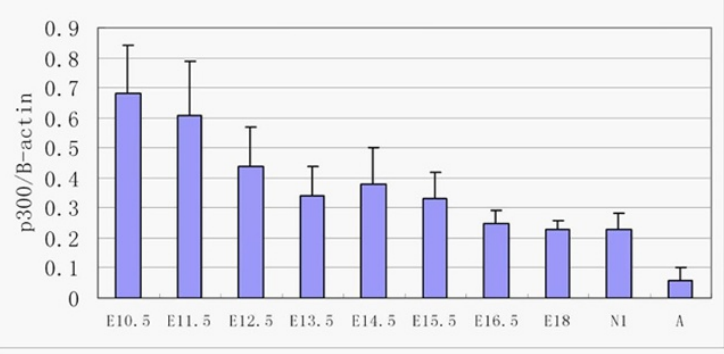

(D)

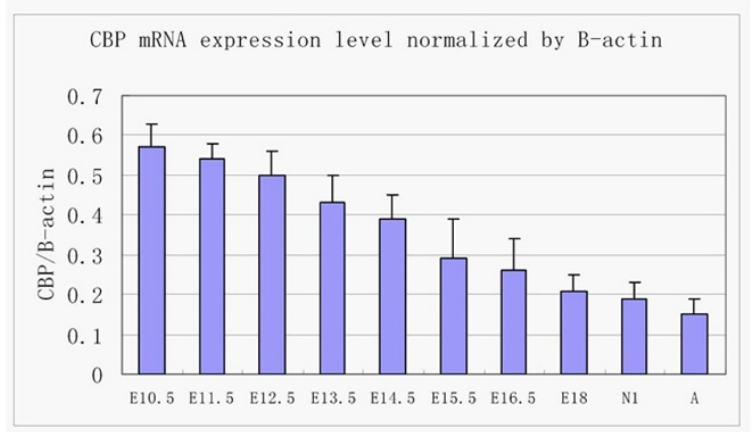

Figure 5

p300 and CBP mRNA expression levels during mouse heart development. RT-PCR data show that p300 (A) and CBP (C) mRNA expressions can be detected at various embryonic stages as well as in postnatal and adult stages. $M$ represents DNA marker. (B, D) The line graphs summarize $\mathrm{p} 300$ (B) and CBP (D) relative expression levels corresponding to panel $A$ and $C$, respectively. Data are expressed as a ratio of 3300 or CBP mRNA to $\beta$-actin mRNA concentrations. Results are averaged from three independent experiments in each stage.

(resulting in lower CBP levels) while the p300 gene of these patients is considered to be normal [15,24,25]. In F9 cells, retinoic acid induced differentiation is dependent on p300 but not on CBP [26]. CBP is found to be localized mainly within the oocyte nucleus while p300 is localized in the cytoplasm after two-cell stage and they could not replace each other in these processes [12]. Moreover, a full complement of CBP, but not p300, is required for normal hematopoietic differentiation $[27,28]$. In consistent with all these reports, our results indicate that there are differences between p300 and CBP in both distribution and temporal expression pattern during the heart development.

\section{Conclusion}

Our data show that the expression of CBP and p300 is developmentally regulated during mouse cardiogenesis. There are differences between CBP and p300 in both tissue distributions and mRNA expression levels during heart development. These observations shed new light on the function of CBP and p300 during heart development and provide us with a molecular basis for further understanding the mechanisms underlying cardiogenesis and some congenital heart diseases.

\section{Competing interests}

The authors declare that they have no competing interests.

\section{Authors' contributions}

GC carried out the immunohistochemical studies and drafted the manuscript. JZ carried out the histological studies for observation of the heart developmental morphology. TL carried out western blotting assays and participated in the sequence alignment experiments. GW carried out the molecular genetic studies using RT-PCR and participated in the sequence alignment experiments. HS performed statistical analysis and participated in drafting the manuscript. XH edited and revised the manuscript 
and participated in the design of the study. JT organized the study and participated in study design and coordination. All authors read and approved the final manuscript.

\section{Acknowledgements}

The authors would like to thank Dr. John, Jang-Yen Wu at Florida Atlantic University for his careful review of the manuscript. This study was supported by research grants from National Natural Science Foundation of China (Grant Number: 30672266) and from Natural Science Foundation of Chongqing (Grant Number: CSTC, 2007BB53II).

\section{References}

I. Olson EN, Schneider MD: Sizing up the heart: development redux in disease. Genes Dev 2003, 17:1937-1956.

2. Webb S, Brown NA, Anderson RH: Formation of the atrioventricular septal structures in the normal mouse. Cir Res 1998, 82:645-656.

3. Delgado-Olguin P, Takeuchi JK, Bruneau BG: Chromatin modification and remodeling in heart development. Scientific World J 2006, 24: $|85|-|86|$.

4. Jenuwein T, Allis CD: Translating the histone code. Science 200 I, 293:1074-1080.

5. Goodman RH, Smolik S: CBP/p300 in cell growth, transformation and development. Genes Dev 2000, 14:1553-1577.

6. Chan HM, Thangue NB: p300/CBP proteins: HATs for transcriptional bridges and scaffolds. J Cell Sci 200 I, I I 4:2363-2373.

7. Liu X, Wang L, Zhao K, Thompson PR, Hwang Y, Marmorstein R, Cole PA: The structural basis of protein acetylation by the p300/CBP transcriptional coactivator. Nature 2008, 45 I:846-850.

8. Giordano A, Avantaggiati ML: p300 and CBP: Partners for life and death. J Cell Physiol 1999, 181:218-230.

9. Partanen A, Motoyama J, Hui CC: Developmentally regulated expression of the transcriptional cofactors/histone acetyltransferases CBP and p300 during mouse embryogenesis. Int J Dev Biol 1999, 43:487-494.

10. Roth JF, Shikama N, Henzen C, Desbaillets I, Lutz W, Marino S, Wittwer J, Schorte H, Sassmann M, Eckner R: Differential role of p300 and CBP acetyltransferase during myogenesis: p300 acts upstream of MyoD and Myf5. EMBO J 2003, 22:5।86-5196.

11. Kalkhoven E: CBP and p300: HATs for different occasions. Biochem Pharmacol 2004, 68: I |45-I I 55.

12. Kwok RP, Liu XT, Smith GD: Distribution of co-activators CBP and p300 during mouse oocyte and embryo development. Mol Reprod Dev 2006, 73:885-894.

13. Kasper LH, Fukuyama T, Biesen MA, Boussouar F, Tong C, De Pauw A, Murray PJ, van Deursen JM, Brindle PK: Conditional knockout mice reveal distinct functions for the global transcriptional coactivators CBP and p300 in T-cell development. Mol Cell Biol 2006, 26:789-809.

14. Yang Y, Wolf LV, Cvekl A: Distinct embryonic expression and localization of CBP and p300 histone acetyltransferases at the mouse alphaA-crystallin locus in lens. J Mol Biol 2007, 369:917-926.

15. Petrij F, Giles RH, Dauwerse HG, Saris Jj, Hennekam RC, Masuno M, Tommerup N, van Ommen G], Goodman RH, Peter DJ: RubinsteinTaybi syndrome caused by mutations in the transcriptional co-activator CBP. Nature 1995, 376:348-35I.

16. Yao TP, Oh SP, Fuchs M, Zhou ND, Chang LE, Newsome D, Bronson RT, Li E, Livingston DM, Eckner R: Gene dosage dependent embryonic development and proliferation defects in mice lacking the transcriptional integrator p300. Cell 1998, 93:36|-372.

17. Tanaka Y, Naruse I, Hongo T, Xu M, Nakahata T, Maekawa T, Ishii S: Extensive brain hemorrhage and embryonic lethality in a mouse null mutant of CREB-binding protein. Mech Dev 2000, 95:133-145.

18. Shikama N, Lutz W, Kretzchmar R, Satuter N, Roth JF, Marino S, Wittwer J, Scheidweiler A, Eckner R: Essential function of p300 acetyltransferase activity in heart, lung and small intestine formation. EMBO J 2003, 22:5I75-5I85.

19. Dominguez JN, Navarro F, Franco D, Thompson RP, Aranega AE: Temporal and spatial expression pattern of betal sodium channel subunit during heart development. Cardiovasc Res 2005, 65:842-850.

20. Lin W, Dent SY: Functions of histone-modifying enzymes in development. Curr Opin Genet Dev 2006, 16:137-142.

21. Ogryzko VV, Schiltz RL, Russanova V, Howard BH, Nakata NY: The transcriptional coactivators $\mathrm{p} 300$ and CBP are histone acetyltransferases. Cell 1996, 87:953-959.

22. Webb S, Brown NA, Anderson RH: The structure of the mouse heart in late fetal stages. Anat Embryol (Berl) 1996, 194:37-47.

23. Lamers WH, Moorman AF: Cardiac septation: a late contribution of the embryonic primary myocardium to heart morphogenesis. Circ Res 2002, 91:93-103.

24. Hennekam RC: Rubinstein-Taybi syndrome. Eur J Hum Genet 2006, I4:98I-985.

25. Roelfsema JH, White SJ, Ariyiirek Y, Bartholdi D, Niedrist D, Papadia F, Bacino CA, Den Dunnen JT, van Ommen G], Breuning MH, Hennekam RC, Peters DJ: Genetic heterogeneity in RubinsteinTaybi syndrome: mutations in both the CBP and EP300 genes cause disease. Am J Hum Genet 2005, 76:572-580.

26. Ugai $H$, Uchida $K$, Kawasaki $H$, Yokoyama KK: The coactivators p300 and CBP have different functions during the differentiation of F9 cells. Mol Med 1999, 77:48I-494.

27. Kung AL, Rebel VI, Bronson RT, Chang LE, Sieff CA, Livingston DM, Yao TP: Gene dose-dependent control of hematopoiesis and hematologic tumor suppression by CBP. Genes Dev 2000, I 4:272-277.

28. Rebel VI, Kung AL, Tanner EA, Yang H, Bronson RT, Livingston DM: Distinct roles for CREB-binding protein and p300 in hematopoietic stem cell self-renewal. Proc Natl Acad Sci USA 2002, 99:14789-14794.
Publish with Bio Med Central and every scientist can read your work free of charge

"BioMed Central will be the most significant development for disseminating the results of biomedical research in our lifetime. "

Sir Paul Nurse, Cancer Research UK

Your research papers will be:

- available free of charge to the entire biomedical community

- peer reviewed and published immediately upon acceptance

- cited in PubMed and archived on PubMed Central

- yours - you keep the copyright

Submit your manuscript here:

http://www.biomedcentral.com/info/publishing_adv.asp
BioMedcentral 